\title{
The Lost Identity of the Trafficked Child Soldier in Young Adult Literature
}

\author{
Faisal Lafee Alobeytha \\ Universiti Utara Malaysia \\ Sintok -Malaysia \\ aserhanfaisal@gmail.com
}

\author{
Faizahani Ab Rahman \\ Universiti Utara Malaysia \\ Sintok -Malaysia \\ faizahani@uum.edu.my
}

\author{
Abdul Halim Mohamed \\ Universiti Utara Malaysia \\ Sintok -Malaysia \\ halim@uum.edu.my
}

\begin{abstract}
This study examines the impact of child soldier trafficking on the identity of the trafficked child soldier, explores the factors that impact on the identity development of the trafficked hero as it appeared in the fiction and sees how the novelist used Young Adult Literature to deal with some young adults' issues as child trafficking. For the purpose of achieving these objectives, young adult novel Iweala's Beast of No Nation (2005) is selected. The framework of this study is based on a Bronfenbrenner's ecological system theory (1994).For analysing the literary text, thematic approach of Braun and Clarke (2006) is used. The study comes to the following findings: the war traffickers always attempt to erase the identities of the trafficked child soldiers and replace it with the identities of the slave soldiers, following diverse sorts of violence as physical and psychological torture is an away to enslave the trafficked children, adopting some changes can rebirth the identity of the trafficked child which assists him or her to escape from those traffickers, the children are easy targets to be recruited as soldiers or rebels, finally, young adult literature is a convenient literature to teach moral lesson.
\end{abstract}

Keywords—child soldier trafficking; identity; rebels; trafficked child; young adult literature

\section{INTRODUCTION}

Age is a very important factor in categorizing the audiences of Young Adult Literature (YAL) and identifying this literature. Unfortunately, there is no consensus on the definition of the age of young adult. Nilsen and Donelson (1996) define YAL as "[a]nything that readers between the approximate ages of twelve and twenty choose to read (as opposed to what they may be coerced to read for a class assignment)" (p.6)[1]. Aubin (1980) introduces YAL as "any piece of prose fiction written specifically for an audience between the ages of twelve and eighteen" [2]. However, there are a lot of people whose ages are more than 18 years and they prefer reading this literature, "The young adult fiction market is huge, spawning book series, films, stars and franchises, and more than half its fans are apparently over 18'[3]. While [4] explains that YAL is written for students from 7-12 grades.
Regarding the goals of YAL, Kaplan (2005) believes that the objective of YAL is to search for the identity of young adults in their literature[5]. The formation of Young Adults' (YA) identities is connected to the YAL in the sense that reading YA novels can cause alterations to their identities, and these changes may affect their physical and emotional conducts. These changes resulted from interactions between YA readers and the texts where the readers may add some personal knowledge to the texts[6]. Adolescents are exposed to diverse sorts of volatile periods in their lives and these might influence their identities.

This paper aims to explore the effect of child soldier trafficking on the identity of the hero Agu (trafficked child soldier in Beast of No Nation), the factors that affect the identity development of Agu and how YAL deals with some adolescents' issues as child trafficking.

\section{LITERATURE REVIEWS}

The topic of child soldier trafficking raids literature generally and becomes one of the essential topics of YAL. Rosen and Rosen (2012) cite that "[c]hild soldiers, or child warriors, also figure prominently in contemporary fiction and film for both children and adults" (p.305)[7]. Nevertheless, few scholars discuss this topic in their studies.

Through the comparative analysis of the African narrative of a child soldier, Coundouriotis (2010) distinguishes between the child soldier novels that were published before and after the mid-1990s. The themes of the novels which published before this date motivate people to resist the colonizer by telling them heroic stories and reminding them of their glorious history. In contrast, the new novels that were published in the years that follow the mid-1990s handle the psychological and physical status of child soldiers [8].

Hron (2008) indicates that most of the protagonists in Nigerian novels have been children and YA since 2000. Numerous of these novels examine some issues such as child trafficking and the identity of the child [9]. The novelists of this generation handle the situation of the child in African 
literature described as lacking identity and social position, Hron ( 2008) cites that "[I]t becomes apparent that the child's quest for a sociocultural identity is inextricably linked to issues arising from postcolonialism and globalization, often manifested in the context of repression, violence or exploitation"(p.29)[10].

\section{METHODOLOGY}

This study used Bronfenbrenner's (1994) Ecological System Theory [11] as the framework to discuss the identity of the trafficked child soldier in Uzodinma Iweala's Beasts of No Nation [12].This theory involves five nests:(1) microsystem, the child's most close environment (parents, school, peers); (2) mesosystem, the continuing interacting between two or more members of microsystem as a relation between the parents and the school; (3) exosystem, the outside setting that has indirect influence a child as the influence of parents' workplace on the child; (4) macrosystem, the impact of norm, law and culture on the child; (5) chronosystem, the effect of the socio-historical situation and alterations over the life of on a child. Regrettably, mesosystem is not going to be discussed in this present research because there is no data that covers the relation between the members of microsystem based on Beasts of No Nation.

This study will use thematic approach of Braun and Clarke (2006) to analyse the text of the novels[13]. This approach involve six steps (familiarizing with the data, generating initial codes, searching for themes, reviewing themes, defining and naming themes and producing the report.

\section{THE IDENTITY OF AGU}

In Beasts of No Nation, a nine-year-old protagonist, Agu, represented the child soldiers in the world. As soon as the rebels raided his village, his idyllic infancy had been changed to a miserable life because of the brutality of rebels who abducted and recruited him as a child soldier. Agu's identity will be analysed under two subsections: the identity of Agu before being trafficked as a child soldier and the identity of Agu as a trafficked child.

\section{A. The Identity of Agu before being Trafficked as a Child Soldier}

1) Microsystem: The microsystem is the scope of direct experience for the person affected by the quantities of resources that have direct social contacts. Agu was influenced by his mother who always told him the history of conflict between human beings, she informed him how Cain killed Abel and how David killed Goliath [11]. These crimes could not be accepted by him as he was still below the age of ten years. His mother aimed to prepare him for the day when the rebels attack their village since she considered the war an inevitable matter. Therefore, his identity was mixed with the feeling of fear and anxiety because these stories had a negative impact on his psychology.

In spite of these stories mirrored the real situation of the countries that witnessed the civil war, they should not be narrated to Agu because his mind was shaped by the stuff that was poured into it. His mind consumed destructive image, words and opinion because they had a negative influence on his outlook and identity. These stores deconstructed his identity because he realized that he could not escape from the death or being trafficked as a child soldier.

2)Macrosystem. It involves law, norms and culture. In Beasts of No Nation, the patriarchal system was based on the notion that gender's authority led to the dominance of males over women and children as well as destitute people. The impact of patriarchal norms on the identity of Agu was very negative. Iweala criticized how the culture dealt with the masculinity and femininity. He also criticized how his society attributed every bad act or behaviour to women while good act and behaviour to men. Agu was careful to do men's work and avoid doing any female's work. For example, Children were taught how to dance since dancing was considered a symbol of manhood. Agu cited that "[i]f you are not learning, then nobody is thinking [sic] that you are man" (pp. $25-26)[11]$. Thus, he convinced the others of his masculinity to escape from the mock of men who degraded the actions of women.

The society of Agu which endorsed carrying weapons as a symbol of masculinity could attract the children to join the terrorist group. Agu and his peers used to play a game that represented the struggle between the soldiers and the terrorists. This game reflected his concept and image of the soldiers and after a short period, it became serious. This game and other similar games deceived the children and fostered their personality with some false ideas.

Agu had a positive image of the soldiers and their noble deeds that aimed to protect the country from the enemy, to rescue the poor people from the terrorists and to preserve the security of the country. In his image, he thought that being a soldier is "the best thing" (p. 31)[11]. It is noted that Agu's macrosystem had a big impact on his behaviour as a soldier since his mind accepted the killing of the others after a little hesitation.

\section{B. The Identity of Agu as a Trafficked Child}

1) Microsystem: The new microsystem involved the commandant and peers who had deconstructed Agu's identity. The commandant used his direct influence to further enforce Agu to kowtow him. He also forced his other child soldiers to convince Agu to behave like them otherwise Agu would be out of the group and he could not get the privileges of child soldiers. The commandant created a policy that anyone who disobeyed him would be taken out of the group and would be treated as enemy or spy. Eventually, he would be killed. To continue to be in the group, the child soldier had to follow the order of the commandant even if this order were to pull the trigger on child soldier' family. Agu admitted how he was ready to do whatever the commandant asked him to do. He mentioned, "[i]f they are ordering me KILL, ... I am killing everybody, mother, father, grandmother, grandfather, soldier[sic]"(p.135)[11].The blind obedience to the 
commandant's orders instilled the concept of slavery in the mind of Agu.

Iweala explained how the commandant deceived Agu to accept joining the rebels by pseudo allegations. The commandant uttered, "[i]f you are staying with me, I will be taking care of you and we will be fighting the enemy that is taking your father [sic]" (p. 13)[11]. In fact, Agu's acceptance and rejection of joining the rebels were meaningless because he was under the threat of commandant's authority. That temptation was just to facilitate and shorten the process of recruitment of children as soldiers.

It is obvious that Agu did not want to join the rebels but he was compelled to be one of the rebels. His dilemma of choosing between being a rebel or death was what Langer (1982) called a "choiceless choice" (p.146)[14]. Agu was recruited as a soldier since he did not own another option. The sole solution was to follow the commandant's order and commit as many brutal crimes as he could in order to gratify his commandant otherwise he will encounter the death.

The commandant's brutal treatment and harsh style in dealing with Agu and other child soldiers had a big impact on their identities. Agu was surprised when he heard the commandant shouting "[w]ho is finding this thing?" (p.6)[11]. To Agu, calling a person by referring to a thing was a kind of contempt. This was the first incident that destroyed Agu's identity and self-esteem.

The materialistic people do not respect the values of human being and they treat the mankind as an object. The commandant looked to the little soldiers as objects and he called them by using the dehumanizing word, "this boy-one skinny little thing like this - is finding this thing here" (p.5)[11]. Using materialistic words to describe people is a kind of affront and it decreases the self-esteem and hastens the deconstructing of the child's identity.

Agu described how the commandant looked at him "I am an ant or some insect" (p.6)[11]. This feeling confirmed how the traffickers looked down to the child soldiers and how the relation between the master and the slave should be. According to the Spivak's theory "Can the subaltern speak"? This situation confirmed how the officers (the commandant) looked down to the subaltern (Agu and other child soldiers). In most cases, the subaltern is marginalized and does not receive the respect[15].

The surprising and fear from the violence of the new microsystem prevented Agu from expressing his real identity by uttering his name in front of the commandant in this scary situation. Under the threat of commandant, he remembered his name and uttered it[11].

Strika found in drawing a picture and writing a specific word a good representation of his awful circumstances that he lived. This picture was a mediation language between him and his close friend Agu, Agu mentioned how Strika expressed his feeling through a picture "drawing the same picture of man and woman with no head because their head is rolling away on the ground" (p.36) [11]. Strika never uttered any sound since his parents were killed. His silence represented his fear from the surrounded environment where he found that it was useless to utter or express his will. Therefore, the identity of Strika was demolished and this demolishing prevented him from even uttering any sound.

Killing for the first time was not easy for Agu who already experienced from watching how his father was killed. He lived a terrible conflict when the commandant ordered him to kill another man. He described how even animals hate human beings' crimes while the commandant was smiling. Iweala presented the aggression of human beings in a lyrical way that created a kind of interaction between the scene of the crimes and the reaction of the birds. He preferred to depict this tragic scene to draw the attention of the audience to the merciful of birds and the savagery of the human beings.

In spite of his being among the rebels as a soldier and committing a lot of massacres, Agu did not forget his school that did not evade from his mind. By education, $\mathrm{He}$ will become a doctor or an engineer, so he expiated his sins by acts of penance that helped his poor people. Agu lived an internal struggle between his crimes that he committed and his willingness to repent because he was afraid that God will not accept his repentance and forgive his crimes.

At certain stages in his gang life, Agu faced moments of remorse for his shameful criminal acts. He admitted he was guilty and there was a need to stand in front of God and ask for his forgiveness. The importance of forgiveness might give Agu a sense of liberation. Feeling remorse was the first step in regaining his identity after it was injured by the commandants and the rebels' environment. Therefore, he resorted to a dialogue with father Festus about the importance and the necessity of a confession and forgiveness. When Agu got rid of all the sins and freed himself, he felt that he opened a gate to an acquittal. Agu wanted to prove to himself that he was still a human being and possessed the characteristics of mankind. His justifying of his crimes based on his believing that a soldier had to obey the order of the commandant.

Homeric laughter was one of the methods that appeared in the novel to make someone feel low self-esteem. When the commandant laughed at someone, the other soldiers had to laugh. This kind of laughing made Agu feel that he was weak and coward. Therefore, to stop their laughing and to prove his bravery, he killed the woman and her daughter. Child soldiers in the novel laughed when they witnessed torment and torture of poor people by the commandant. For example, killing the innocent man who was described by the commandant as the enemy made those soldiers laugh maniacally just to gratify the arrogance of the commandant.

Soldiers' laughter and the screaming of the civilian victims integrated the comic scene and tragic scene in one complex scene. The first one represented the happiness of the commandant and the blind obedience of the child soldiers who were forced to laugh to satisfy the commandant. In contrast, the second scene represented the wretched situation of the victims who were crying from the torments and begged the commandant the compassion and mercy. The complex scene was portrayed in Agu saying " [B]ullet was just sounding so loud and there was so much screaming, shouting and laughing (p.71)[11]. The screaming words always came to convey a 
letter to the criminals that the victims did not have more screaming. This was the only weapon that the victims used it to defend themselves[11] .

2) Macrosystem: The goals of rebels are usually pertaining to the materialistic factors. The commandants of the rebels adopt them to provoke their soldiers to fight, and they betray them by some false values that decorate their allegations of striking the war. They simply gather the fortune for themselves and prevent the other from it. It is embedded that fighting the commandant means fighting the materialistic people who enslaved the others in order to satisfy their material needs. Iweala exhibited how the government fought the commandant's forces in order to protect the country from ruin and to protect the wealth of the villagers. Iweala reveals how the commandant refused to declare a ceasefire or stop fighting because this would not serve his materialistic interests and he would lose his prestigious status as a commandant.

Iweala paid the attention of the world to the importance of rehabilitation of those child soldiers who got rid of their weapons. Those children should resort to a convenient shelter that protected, educated, and took care of them. They should be trained and educated in order to get suitable jobs otherwise they will resort to atrocities and crimes to survive. Agu assured that he was lost although he has a map, he did not know how it could guide him to the safe beach [11]. The rehabilitation assisted the trafficked child to improve his identity and to cure of the consequences of child trafficking.

The international effort to stop the civil war should concentrate on the rebuilding of the education structure in order to educate the children; otherwise, the risks of child trafficking will increase. Agu was crying when his school was closed because of the war and he criticized the world for their salience towards the civil war. Agu invited the world to work to stop the civil war, he cites "I am wanting to open my mouth and scream so that everybody is waking up and listening to all of the trouble this war is bringing" (p.62)[11].

3) Chronosystem: The effect of chronic violence on the identity of Agu was very negative. This pushed him to admit that he was a slave when he compared himself to the small trees that serve the vine trees "I am more like the slave tree because I can never be doing what I want" (Iweala, 2005, p.42). He felt sad, depressed, hopeless, scared and brokenhearted because he lived without free will and he could not express his opinion or reject the order of the commandant. He did not feel proud of himself because he was a tool that used to kill the innocent people based on the order of the commandant. He wished that he was like the Iroko tree because it is tall and can control the others, while he was a slave and could not control anything even his body.

The long-staying among rebels and committing many crimes made Agu think that his crimes were normal and part of his military duties. He was betrayed by the commandant who convinced him that he was a soldier with military moral and principles. Thus, his acts were not considered crimes since the soldiers do like these everywhere. Agu wanted to reject the growing uncertainty on his moral and human behaviour by justifying why he does the atrocities, " 1 am telling this to myself because soldier is supposed to be killing, killing, killing[sic]" (p. 23)[11]. By continuing committing crimes, he felt that the returning road to his humanity was far.

This immersion in the oppressive and aggressive deeds inspired Agu that he became a monster since he is accustomed to seeing the scene of brutality. This disgraceful of self that Agu owned is clarified by Hron (2008) when she cited, "Given the atrocities he has seen and committed, he has grown beyond the world of adulthood and entered into the realm of the monstrous" ( p. 43)[9].

The child soldiers deceived themselves and adopted a false idea; this is called self- deception which means accepting claims about themselves as right or legal while these claims are untrue or illegal. Child soldiers convinced themselves that their future would be better when they defeated the enemies. The continuing of self-deception as a result of long service as a rebel appeared obviously when Agu and his campaigns started to mimic the real soldiers. They liked to own guns, knives and alcohol as the commandant who possessed these things. By possessing these weapons, they could own the power and authority in order to be good soldiers. They were proud to have a special nickname such as Rambo who got this name from the movies where the protagonists were strong [11].

The novelist Iweal gave a hope to the child soldiers that they can free themselves if they have strong identities and in this case, they will have high self-esteem even if they stay for a long time among the rebels. The novelist immersed one good important answer to Spivak theory's Can The Subaltern Speak? The answer came (Yes), they can. In fact, those child soldiers (the subalterns) rejected being slaves to the commandant and they made their decision when they killed $\operatorname{him}[15]$.

\section{CONCLUSION}

Iweala succeeded in demonstrating the diverse forms of violence that the child soldier (Agu) was exposed to and how these altered his identity and character. Iweala revealed that the traffickers always wanted to erase the identity of child soldiers in order to subjugate them to their powers. He also confirmed the role of different ecological systems in changing the identity of Agu into the identity of criminal and slave. This novel ascertained that recalling the lost identity is possible. It also confirms that YAL can treat all the issues that pertaining YA through raising the awareness of child trafficking among the readers.

\section{REFERENCES}

[1] P.,A.Nilsen and K.,L., Donelson, Literature for today's young adult, London, United Kingdom: Scott Foresman,1996.

[2] P. Aubin, P, The young adult novel in American schools 1930-1980. (Doctoral dissertation), Boston, MA: Boston University, 1980. 
[3] E, Pender, The rise of young adult fiction, (2013). Retrieved from: http://www.litro.co.uk/2013/06/the-rise-of-young-adult-fiction/

[4] K. Latrobe, " An introduction to ten outstanding young adult authors in the United States", World Literature Today,vol 78, I 3, pp. 68-73, 2002.

[5] J.S.Kaplan, "Young adult literature in the 21st century: Moving beyond traditional constraints and conventions", 2005, retrieved from https://scholar.lib.vt.edu/ejournals/ALAN/v32n2/kaplan.pdf

[6] W.Iser, "The implied reader: Patterns of communication in prose fiction from

Bunyan to Beckett". Baltimore, MD: Johns Hopkins University, 1974.

[7] S.M, Rosen and D.M, Rosen, "Representing child soldiers in fiction and film", Peace Review, vol 24,I 3, pp. 305-312, 2012.

[8] E.Coundouriotis, "The child soldier narrative and the problem of arrested historicization .Journal of Human Rights, vol 9,I1,pp.191206,2010 .

[9] H.D. Santoso. An Actantial and Functional Structure Hear My Cry. JEES (Journal of English Educators Society, 2(2), pp.135-144, 2017.

[10] M. Hron, Orana-azunwa: The figure of the child in third-generation Nigerian novels. Research in African Literatures, vol 39,I2, pp. 2748,2008 .

[10] U. Bronfenbrenner, “ Ecological Models of Human Development. Readings on the development of children", vol 2,I1,pp. 37-43, 1994.

[11] U. Iweala, "Beasts of No Nation". London, U.K: John Murray,2005

[12] V. Braun, and V.Clarke, "Using thematic analysis in psychology". Qualitative research in psychology, vol3,I2, pp. 77101,2006 .

[13] L.L.Langer, "Versions of survival: The holocaust and the human spirit". New York, NY. State University of New York,1982.

[14] G.C.Spivak, G, C, "Can the subaltern speak?" in C,Nelson and L,Grossberge, Eds. Marxism and the Interpretation of Culture. London, UK: Macmillan,1988, pp.271-350. 